\title{
Patterns of food acquisition in Brazilian households and associated factors: a population-based survey
}

\author{
Dirce M Marchioni ${ }^{1,2, *}$, Rafael M Claro ${ }^{1,2}$, Renata B Levy ${ }^{1,3}$ and Carlos A Monteiro ${ }^{1,2}$ \\ ${ }^{1}$ Núcleo de Pesquisas Epidemiológicas em Nutrição e Saúde, Faculdade de Saúde Pública, Universidade \\ de São Paulo, Av Dr Arnaldo 715, Cerqueira César, São Paulo, SP, Brasil, CEP 01246-904: ${ }^{2}$ Departamento de \\ Nutrição, Faculdade de Saúde Pública, Universidade de São Paulo, São Paulo, SP, Brasil: ${ }^{3}$ Departamento de \\ Medicina Preventiva, Faculdade de Medicina, Universidade de São Paulo, São Paulo, SP, Brasil
}

Submitted 13 0ctober 2010: Accepted 9 February 2011: First published online 13 April 2011

\begin{abstract}
Objective: To identify food acquisition patterns in Brazil and relate them to the sociodemographic characteristics of the household.

Design: A cross-sectional national Household Budget Survey (HBS). Principal component factor analysis was used to derive food patterns (factors) on the basis of the acquisition of food classified into thirty-two food groups.

Setting: The source of data originates from the 2002-2003 HBS carried out by the Brazilian Institute of Geography and Statistics between June 2002 and July 2003 using a representative sample of all Brazilian households.

Subject: A total of 48470 households allocated into 443 strata of households that were geographically and socio-economically homogeneous as a study unit.

Results: We identified two patterns of food acquisition. The first, named 'dual', was characterized by dairy, fruit, fruit juice, vegetables, processed meat, soft drinks, sweets, bread and margarine, and by inverse correlations with Brazilian staple foods. In contrast, the second pattern, named 'traditional', was characterized by rice, beans, manioc, flour, milk and sugar. The 'dual' pattern was associated with higher household educational level, income and the average age of adults on the strata, whereas the 'traditional' presented higher loadings in lesseducated households and in the rural setting.

Conclusions: Dietary patterns described here suggest that policies and programmes to promote healthy eating need to consider that healthy and non-healthy foods may be integral in the same pattern.
\end{abstract}

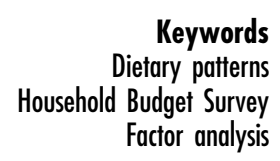

Keywords Budget Survey Factor analysis
To cope with the increasing rates of obesity, CVD, diabetes mellitus and cancer, one of the main objectives of the Brazilian food and nutritional policy is to reduce health damages related to diet in the population ${ }^{(1)}$. To achieve this goal, there is a need to understand the main population dietary patterns. Various sociodemographic factors such as income, education, sex and ethnicity are thought to influence food choices. Traditionally, research on diet and health has focused on single nutrients or on single food items, and not on the entire diet. Since we eat food, not single nutrients or food items, the focus has recently turned more towards dietary patterns ${ }^{(2,3)}$. Thus, the study of dietary patterns using multivariate data analysis, e.g. factor analysis, is burgeoning in nutritional research. Factor analysis is a statistical method that analyses the covariate structure of a range of variables to identify a restricted number of underlying variables. When applied to the analysis of food group consumption, exploratory factor analysis reduces data into patterns based on correlation between dietary items ${ }^{(4)}$.
Studies regarding food or nutrient intake have reported changes in dietary intake and food consumption in Brazil. Levy-Costa et al. ${ }^{(5)}$, on the basis of data from Household Budget Surveys (HBS) on food, reported, in a 30-year interval: a decline in the consumption of basic, traditional foods such as rice and beans; notable increases (up to $400 \%$ ) in the consumption of processed food items, such as cookies and soft drinks; maintenance of excessive consumption of sugar; and a continuous increase in total fat and saturated fat contents in the diet. However, few studies have examined entire dietary patterns.

The aim of the present study was to identify and analyse the main dietary patterns prevailing in Brazil using data from a national HBS.

\section{Methods}

All data analysed in the present study originate from the 2002-2003 HBS carried out by the Brazilian Institute of 
Geography and Statistics between June 2002 and July 2003 using a representative sample of all Brazilian households. The data collected in this survey describe in considerable detail all food purchases made by families throughout a 12-month period.

\section{Sampling}

The present study is based on the analysis of data collected from the 2002-2003 HBS on a probabilistic sample of 48470 Brazilian households ${ }^{(6)}$. This survey used a complex clustered sampling procedure, with a random selection of Census tracts in the first stage and of households within those tracts in the second. Selection of Census tracts was preceded by an examination of the 215790 tracts of the 2000 Demographic Census in order to obtain strata of households with high geographic and socio-economic homogeneity. For this classification, the geographical location of tracts (region, state, capital city or other, urban or rural) and, within each geographical locus, the variation in years of schooling of heads of households in the sector (obtained during the 1996 population count) were considered. Finally, 443 strata of households that were geographically and socio-economically homogeneous were constituted. The number of tracts selected from within each stratum was proportional to the total number of permanent private households in that stratum, with a minimum of two tracts selected per stratum. Next, households were selected within each tract by simple random sampling without reposition. Interviews within each selected stratum were distributed uniformly across the four trimesters of the study so as to reproduce, within each stratum, the seasonal variation in income, prices and purchase of food and other products.

\section{Data collection}

The main component of data from the 2002-2003 HBS used in the present analysis comprises the records of seven consecutive days of food purchases for consumption by the household. Purchases were recorded in a booklet by the household members under the daily supervision of the interviewer from the Brazilian Institute of Geography and Statistics. The short reference period used by the HBS for recording household food expenditures does not allow the identification of the usual food purchase patterns of each individual household. To overcome this limitation, in the present analysis we used the set of households visited within each of the 443 strata in the sample as a study unit. The mean number of households studied within each study unit was 109.4 (range: 9-804).

\section{Variable creation and definition}

In order to establish the amounts of the different foods purchased within each study unit (household stratum), we added all records for the same food by each household in the study unit. In the end, approximately 1300 different foods and beverages were computed. When appropriate, we excluded the inedible fraction of foods using the corresponding correction factors ${ }^{(7)}$. We then converted the total amount of each purchased food into energy (kJ) and selected nutrients (protein, carbohydrate, fat, retinol, fibre, vitamin C, cholesterol, $\mathrm{Ca}, \mathrm{Fe}$ and saturated fat) using AQUINUT software version 1.0 (Núcleo de Pesquisas Epidemiológicas em Nutrição e Saúde - NUPENS, Sao Paulo, Brazil) ${ }^{(8)}$, generated predominantly using TACO (the Brazilian food composition table) ${ }^{(9)}$. For foods not included in this table, we used the US official food composition table, version $15^{(10)}$.

The food items were categorized into thirty-two food groups according to categories of foods with similar nutritional content and the frequency of purchase: sugar and sweeteners, soft drinks, biscuits, desserts and sweets, processed meat, chicken, beef meat, pork meat, fish, rice, wheat flour, pasta, corn, bread, banana, orange, other fruits (all fruits, except orange and banana), fruit juices, butter and margarine, milk, dairy products, pulses, oil, eggs, ready-toeat meals, potatoes, manioc, manioc flour, lettuce, other green vegetables (all greens, except lettuce), tomato and other vegetables (all vegetables, except tomato).

The mean family income in the stratum, expressed in \$US/person per month, was obtained by dividing the sum of the monthly incomes of all households in the stratum by the total number of persons living in these households. In a similar manner, we calculated the mean age and mean years of schooling of residents for each stratum. The geographical region where the stratum was located (north, north-east, south, south-east and mid-west) and its rural/urban status complemented the characterization of the study units.

\section{Statistical methods}

Principal component factor analysis was used to derive food patterns (factors) on the basis of the acquisition of the thirty-two food groups. The first pattern extracted accounts for the maximum possible variance in the data set. The second, independent of the first, explains the maximum possible for the remaining variance, and so on, without any correlation between the components ${ }^{(11,12)}$. A stepwise procedure was utilized to determine the number of patterns to be extracted. Initially, the patterns with eigenvalues over $1 \cdot 25$ were retained, resulting in six factors. In a second step, the Scree Test criterion was used, by examining the shape of the screeplot to define the cut-off point. Finally, the criterion of interpretability was considered ${ }^{(11,12)}$. After this process, labels were assigned to each pattern retained on the basis of an approximate description of the food items that were most highly represented ${ }^{(13,14)}$.

Orthogonal Varimax rotation was applied to achieve a simpler structure with greater interpretability. Factor loadings of $>0.25$ were considered to significantly contribute to the pattern. Within each pattern, negative loadings indicate that the food group is inversely associated 
with the pattern, whereas positive loadings indicate a direct association. The higher the factor loading of a food group the greater the contribution of that group to the pattern, since the square of the factor loading corresponds to the percentage variance of the food group that is explained by the pattern. Factor scores - a composite measure created for each study unit on each pattern retained $^{(11)}$ - were used to study the relationship between patterns and the sociodemographic and socio-economic aspects of the strata. The following variables were used: urban or rural strata and average adult age, education and income. All the continuous variables used in the present analysis - representing the average values of the strata were categorized according to tertiles of their distribution.

As orthogonal rotation of all patterns retained the guarantee that they are uncorrelated, the sum of the square correlations between absolute nutrient availability and factor scores can be interpreted as the proportion of variance of the nutrient availability that is explained by the patterns ${ }^{(14)}$. The same analysis was conducted with energy-adjusted nutrient availability, using the residual method, obtained on the basis of the residuals of linear regression models that have the acquired amount of each nutrient as the outcome variable and total energy as the explanatory variable ${ }^{(15)}$. We used Cronbach's $\alpha$ coefficient to evaluate internal consistency for each component. All analyses were carried out using the Stata/IC statistical software package version $9 \cdot 2$ for Windows (StataCorp., College Station, TX, USA). Two-sided significance was determined at $P<0 \cdot 05$.

\section{Results}

Table 1 presents the sociodemographic and socioeconomic characteristics of the household strata. The vast majority lived in urban areas (85\%) and $45 \%$ in the southeast region. Mean per capita monthly income was \$US 269 , and for one-third of the household strata the monthly income was \$US 148 or less. The mean composition of the households was 3.6 members, aged nearly 30 years, and approximately a quarter were headed by women. Individuals under 20 years formed $38 \%$ of the households. The mean number of years of schooling was 7 .

Two patterns were retained in the factor analysis, which accounted for $42 \%$ of the variance in food acquisition (Table 2). The first was responsible for $29 \%$ and the second for the additional $13 \%$ of total variance.

The factor loadings of each food group in each pattern are presented in Table 2. On the basis of the factor loadings of each food group in each of the two retained patterns, we called the first 'dual pattern' and the second 'traditional pattern'. The dual pattern had significant contributions (factor loadings $>0.25$ ) from dairy, fruit, tomato, orange, vegetables, fruit juice, green vegetables and banana, food items that are recognized as positively related to health, and also from foods that have been associated with deleterious effects on health, such as desserts and sweets, soft drinks, processed meat, readyto-eat meals, margarine and biscuits. Further, this pattern presented inverse correlations with Brazilian staple foods. The traditional pattern had significant contributions from

Table 1 Demographic and economic characterization of the study units, Brazil, 2002-2003

\begin{tabular}{lcc}
\hline & $n$ & Household strata $(n$ 443) \\
\cline { 2 - 3 } Indicator & & \\
\hline Area & 323 & $84 \cdot 8$ \\
Urban & 120 & $15 \cdot 2$ \\
Rural & & $6 \cdot 5$ \\
Region & 95 & $25 \cdot 2$ \\
North & 146 & $45 \cdot 1$ \\
North-east & 93 & $16 \cdot 0$ \\
South-east & 52 & $7 \cdot 2$ \\
South & 57 & $33 \cdot 3$ \\
Centre-east & 169 & $34 \cdot 1$ \\
Monthly per capita income (\$US) & 111 & $32 \cdot 6$ \\
34-148 & 163 & $5 \mathrm{SE}$ \\
148-240 & & $0 \cdot 29$ \\
$\geq 240$ & Mean or $\%$ & $0 \cdot 27$ \\
& $29 \cdot 1$ & $0 \cdot 32$ \\
Age (years) & $28 \cdot 4$ & $0 \cdot 6$ \\
Male & $29 \cdot 8$ & $0 \cdot 2$ \\
Female & $26 \cdot 1$ & $0 \cdot 00$ \\
Percentage of women as heads of households & $50 \cdot 5$ & $0 \cdot 3$ \\
Percentage of women in the stratum population & $3 \cdot 6$ & $0 \cdot 3$ \\
Number of householders & $8 \cdot 8$ & $15 \cdot 41$ \\
Percentage of individuals over 64 years & $6 \cdot 3$ & $0 \cdot 16$ \\
Percentage of individuals under 5 years & $269 \cdot 0$ & $6 \cdot 7$ \\
Average monthly per capita income (\$US) & & \\
Schooling - adults (completed number of years) & & \\
\hline
\end{tabular}


Table 2 Factor loadings for the two factors found in the principal component analysis

\begin{tabular}{|c|c|c|c|c|c|c|c|}
\hline \multirow[b]{2}{*}{ Food item } & \multicolumn{3}{|c|}{ Dual pattern } & \multirow[b]{2}{*}{ Food item } & \multicolumn{3}{|c|}{ Traditional } \\
\hline & $\begin{array}{c}\text { Percentage of } \\
\text { variance }\end{array}$ & Cronbach's $\alpha$ & $\begin{array}{l}\text { Factor } \\
\text { loading }\end{array}$ & & $\begin{array}{l}\text { Percentage of } \\
\text { variance }\end{array}$ & Cronbach's $\alpha$ & $\begin{array}{l}\text { Factor } \\
\text { loading }\end{array}$ \\
\hline & 29 & 0.93 & & & 13 & $0 \cdot 78$ & \\
\hline Dairy & & & $0 \cdot 86$ & Sugar & & & 0.69 \\
\hline Sweets & & & 0.85 & Pork & & & 0.69 \\
\hline Fruit & & & $0 \cdot 84$ & Wheat flour & & & 0.69 \\
\hline Soft drinks & & & $0 \cdot 80$ & Milk & & & 0.68 \\
\hline Tomato & & & 0.75 & Rice & & & 0.63 \\
\hline Ready-to-eat meals & & & $0 \cdot 75$ & Vegetable oil & & & 0.63 \\
\hline Orange & & & $0 \cdot 73$ & Manioc & & & 0.59 \\
\hline Vegetables & & & $0 \cdot 70$ & Beans & & & 0.47 \\
\hline Processed meat & & & $0 \cdot 70$ & Corn & & & 0.36 \\
\hline Potatoes & & & 0.69 & Green vegetables & & & 0.36 \\
\hline Fruit juices & & & 0.68 & Potatoes & & & 0.32 \\
\hline Bread & & & 0.67 & Pasta & & & 0.30 \\
\hline Margarine & & & 0.64 & Lettuce & & & 0.30 \\
\hline Green vegetables & & & 0.62 & Eggs & & & 0.27 \\
\hline Banana & & & 0.59 & Bread & & & -0.35 \\
\hline Biscuits & & & 0.44 & & & & \\
\hline Milk & & & 0.29 & & & & \\
\hline Lettuce & & & 0.28 & & & & \\
\hline Sugar & & & -0.28 & & & & \\
\hline Rice & & & -0.31 & & & & \\
\hline Beans & & & -0.39 & & & & \\
\hline Corn & & & -0.43 & & & & \\
\hline Manioc flour & & & -0.44 & & & & \\
\hline
\end{tabular}

Table 3 Mean factor score in each food acquisition pattern, by area of residence, family income, age and years of schooling

\begin{tabular}{|c|c|c|c|c|c|c|}
\hline \multirow[b]{3}{*}{ Household characteristic } & \multicolumn{6}{|c|}{ Food acquisition pattern } \\
\hline & \multicolumn{3}{|c|}{ Dual } & \multicolumn{3}{|c|}{ Traditional } \\
\hline & Mean & Tertile & $P$ value & Mean & Tertile & $P$ value \\
\hline \multicolumn{7}{|l|}{ Area } \\
\hline Urban & 0.18 & $0.26 ; 0.33$ & \multirow[t]{2}{*}{$<0.01$} & -0.20 & $-0.33 ; 0.07$ & \multirow[t]{2}{*}{$<0.01$} \\
\hline Rural & -0.99 & $-1 \cdot 26 ;-0 \cdot 74$ & & $1 \cdot 13$ & $0.61 ; 1.65$ & \\
\hline \multicolumn{7}{|c|}{ Monthly family income (\$US) } \\
\hline $34-148$ & -0.80 & $-0.90 ;-0.69$ & \multirow[t]{3}{*}{$<0.01$} & 0.00 & $-0.22 ; 0.23$ & \multirow[t]{3}{*}{$0 \cdot 265$} \\
\hline $148-240$ & $-0 \cdot 13$ & $-0.25 ;-0.01$ & & 0.32 & $-0.01 ; 0.65$ & \\
\hline$\geq 240$ & 0.88 & $0 \cdot 71 ; 1 \cdot 04$ & & $-0 \cdot 16$ & $-0.35 ; 0.02$ & \\
\hline \multicolumn{7}{|l|}{ Adult age (years) } \\
\hline $19 \cdot 6-27 \cdot 5$ & -0.64 & $-0.81 ;-0.48$ & \multirow[t]{3}{*}{$<0.01$} & -0.27 & $-0.45 ;-0.11$ & \multirow[t]{3}{*}{$<0.01$} \\
\hline $27 \cdot 5-30 \cdot 1$ & -0.23 & $-0.36 ; 0.09$ & & 0.07 & $-1 \cdot 13 ; 0 \cdot 28$ & \\
\hline $30 \cdot 1-49 \cdot 3$ & $1 \cdot 00$ & $0 \cdot 81 ;-1 \cdot 20$ & & $0 \cdot 23$ & $-0.06 ; 0.52$ & \\
\hline \multicolumn{7}{|c|}{ Years of schooling among adults } \\
\hline $1 \cdot 3-5 \cdot 8$ & -0.83 & $-0.97 ;-0.71$ & $<0.01$ & 0.38 & $0.08 ; 0.68$ & $<0.01$ \\
\hline $5 \cdot 8-7 \cdot 3$ & -0.00 & $-0.27 ; 0.26$ & & -0.09 & $-0.34 ; 0.16$ & \\
\hline $7 \cdot 3-14 \cdot 3$ & $0 \cdot 86$ & $0.68 ; 1.03$ & & $-0 \cdot 30$ & $-0.45 ;-0.14$ & \\
\hline
\end{tabular}

food groups used for domestic food preparation, such as rice, beans, pork, eggs, manioc, potato, corn, green vegetables, lettuce, vegetable oil, sugar, meat, pulses, vegetables, roots (manioc) and tubers (potato). In addition, a significant negative factor loading for bread was observed, meaning that the purchase of this food item was contrary to this pattern.

A high internal consistency of food items in each pattern was observed, according to Cronbach's $\alpha$ : 0.93 for the dual pattern and 0.78 for the traditional pattern.

Table 3 presents the mean household factor score in each food acquisition pattern, stratified according to household sociodemographic characteristics. Positive score means on the dual pattern were observed in urban areas, whereas these means were negative in rural areas. The inverse was observed for the traditional pattern. The dual pattern was positively associated with mean household family income $(P<0 \cdot 001)$, whereas no significant association was observed for the traditional pattern. In the second tertile of income, a positive mean was observed; however, in the highest tertile this mean was negative. For educational level, a positive association emerged for the dual pattern and an inverse for the traditional pattern. 
Table 4 Pearson's correlation coefficients between household factor score in each pattern and energy and nutrient availability and percentage of explained variance of energy and nutrient availability in the study sample

\begin{tabular}{|c|c|c|c|c|c|}
\hline & \multicolumn{4}{|c|}{ Dietary pattern } & \multirow{3}{*}{$\begin{array}{c}\text { Total } R^{2} \\
\text { (percentage of variance) } \dagger\end{array}$} \\
\hline & \multicolumn{2}{|c|}{ Dual } & \multicolumn{2}{|c|}{ Traditional } & \\
\hline & Crude & Energy adjusted & Crude & Energy adjusted & \\
\hline Energy (kJ) & $0 \cdot 10$ & - & $0 \cdot 80^{*}$ & - & 65 \\
\hline Protein $(\mathrm{g} / \mathrm{d})$ & $0 \cdot 10^{\star}$ & $0 \cdot 28^{\star}$ & $0 \cdot 74^{\star}$ & 0.29 & 56 \\
\hline Carbohydrate $(\mathrm{g} / \mathrm{d})$ & $-0 \cdot 30^{\star}$ & $-0 \cdot 24^{\star}$ & $0 \cdot 72^{\star}$ & -0.28 & 61 \\
\hline Fat $(g / d)$ & $0.39^{\star}$ & $0.52^{*}$ & $0.73^{*}$ & 0.56 & 69 \\
\hline Retinol $(\mu \mathrm{g})$ & 0.52 & 0.85 & $-0 \cdot 13^{*}$ & $-0.91^{*}$ & 29 \\
\hline Fibre $(g)$ & $0 \cdot 08^{*}$ & $0 \cdot 42^{*}$ & $0.52^{\star}$ & $0 \cdot 42^{*}$ & 28 \\
\hline Vitamin C (mg) & $0 \cdot 77^{\star}$ & $0 \cdot 40^{\star}$ & $0 \cdot 20$ & 0.52 & 63 \\
\hline Cholesterol (mg) & $0 \cdot 37^{\star}$ & $0 \cdot 33^{*}$ & $0 \cdot 46^{\star}$ & $0 \cdot 36$ & 35 \\
\hline $\mathrm{Ca}(\mathrm{mg})$ & $0.43^{\star}$ & $0 \cdot 31^{*}$ & $0 \cdot 69^{\star}$ & $0 \cdot 37^{*}$ & 66 \\
\hline $\mathrm{Fe}(\mathrm{mg})$ & $0 \cdot 43^{*}$ & $0.52^{*}$ & $0.48^{*}$ & 0.58 & 42 \\
\hline Saturated fat $(\mathrm{g})$ & $0.57^{\star}$ & $0 \cdot 49^{\star}$ & $0 \cdot 67^{*}$ & $0 \cdot 62$ & 77 \\
\hline Added sugar (g) & $0.02^{*}$ & $0.48^{\star}$ & $0 \cdot 74^{*}$ & $0.48^{*}$ & 55 \\
\hline
\end{tabular}

${ }^{\star} P<0 \cdot 05$.

tFrom crude Pearson's coefficient.

The two retained patterns accounted for a relatively large proportion of variance $(>50 \%)$ of the following nutrients: energy, protein, carbohydrate, fat, fibre, vitamin $\mathrm{C}, \mathrm{Ca}$ and saturated fat and added sugar (Table 4). The correlations between the score of household dual pattern and selected nutrients after adjustment for energy were positive for protein, fat, cholesterol, saturated fat and added sugar, and also for fibre, vitamin $\mathrm{C}$, Ca and Fe. Related to the traditional pattern, after adjustment for energy, there were positive associations only for fibre, $\mathrm{Ca}$ and sugar addition, whereas the pattern was negative for retinol. Despite the significant association observed with the traditional pattern, the percentage of variance explained for fibre and retinol was relatively low compared with the other nutrients: $<30 \%$.

\section{Discussion}

The present analysis identified two food acquisition patterns in Brazil and explored their relationship with household sociodemographic characteristics and nutrient availability. The first pattern, named 'dual', was characterized by dairy, fruit, fruit juice, vegetables, processed meat, soft drinks, sweets and bread and margarine, and by inverse correlations with Brazilian staple foods. In contrast, the second 'traditional' pattern was characterized by food groups usually used in domestic preparation and cooking of Brazilian traditional dishes, such as rice, beans, manioc, flour, milk and sugar.

Although several dietary patterns have been reported in the literature, two patterns were relatively dominant and were first introduced by Slattery et al. ${ }^{(13)}$ in 1998. The first, a pattern characterized by high intakes of vegetables and fruit, and also of whole grains and white meat or fish, was frequently named as a 'prudent', 'health' or 'health conscious' pattern $^{(16)}$. The other is a culturally dependent 'traditional' pattern, reflecting ethnic differences in food preferences, as reported in North America ${ }^{(17-19)}$, Europe ${ }^{(20-22)}$, Asia $^{(23-26)}$ and Latin America ${ }^{(27-30)}$. Our study has also identified one traditional pattern composed of foods that are Brazilian staple foods, such as rice and beans.

A traditional pattern was also reported in previous studies conducted in Brazilian regions ${ }^{(27,28,30,31)}$. However, what merits attention in our study is the presence of a dual pattern characterized by the simultaneous presence of healthy and unhealthy foods. A similar pattern was found by a longitudinal study conducted in the $\mathrm{USA}^{(32)}$, which reported a pattern rich in components that are considered as having the potential capacity to lower the risk of CVD, but it was not considered as exclusively health promoting. The absence of a coherent health conscious pattern in our study may indicate that the choices of food selection in Brazil are being driven not by health concerns but by tradition, cost, palatability and even food advertisement.

In our study, the traditional pattern was likely to be stronger in the rural setting, similar to the results reported in the $\mathrm{USA}^{(33)}$. The dual pattern was typical in the urban area, in families with monthly income higher than \$US 240 and mean adult age above 30 years. Dietary patterns are likely to vary according to sex, socio-economic status and ethnicity ${ }^{(34-37)}$. In our study, the dual pattern was associated with higher educational level and higher income. Fan et al. ${ }^{(38)}$, using data from the Consumer Expenditure Survey conducted in the USA, described eight food expenditure patterns that were affected by age, ethnicity, education, gender or family type. Hu et $a l^{(36)}$ in a large study in US men reported that individuals who had higher scores for a 'Western' dietary pattern were more likely to have lower levels of income and education. Our results of the dual pattern are similar to those of previous studies, in which patterns with high loadings in fruit and vegetables were frequently positively associated with 
age $^{(33,39,40)}$, higher income, higher educational levels ${ }^{(41)}$ or higher socio-economic status, sometimes in a genderspecific manner. Cai et al. ${ }^{(39)}$, in Shanghai, reported that more educated people had higher scores for all three patterns retained. The relationship of dietary patterns to sociodemographic and lifestyle characteristics supports the theory that food choices are part of a larger pattern of health-related characteristics and behaviours.

The dual pattern described here, similar to other studies on Mexican Americans, British and Hawaiians ${ }^{(26,42,43)}$, suggests high risk for chronic diseases in a part of the Brazilian population. High availability of sweets, cookies, soft drinks and processed meat was observed in the dual pattern, which accounted for almost one-third of the variability in our sample (Table 2), despite expenditure on fruit and legumes, which was observed in this pattern. The traditional pattern presented high correlations with the two food items that form one of the most common dishes in Brazil, rice and beans, also considered a healthy dish, the intake of which is promoted by the Brazilian Health Minister ${ }^{(44)}$.

The dual pattern presented strong correlations with vitamin $\mathrm{C}$ and retinol, markers of the intakes of fruit and vegetables, whereas the traditional pattern was highly correlated with energy, macronutrients (fat, protein and carbohydrate) and cholesterol, and also with fibre, probably because of the contribution of bean intake, the availability of which was estimated at approximately $46 \mathrm{~g} / \mathrm{d}$ in the highest quintile (data not shown). The significant correlation values observed between the scores of the dual pattern and energy-adjusted nutrients (Table 3) seem to reinforce the concurrent participation of food in this pattern which has an antagonistic role in health; for instance, fat and vitamin C.

Some points should be considered in interpreting the findings of the present study. Our data refer to food acquisition information, rather than to dietary intake, information available on HBS. However, studies comparing the results from HBS with those of individual intake surveys have found considerable agreement between the two methods ${ }^{(45,46)}$. This analytical strategy of aggregating households was chosen to overcome the impact that the short reference period used by the Brazilian HBS to record the food acquisition data (seven consecutive days) would have. This period, relatively common in budget surveys, does not provide reliable figures on the food acquisition pattern existing in each household. However, we used geographically and socio-economically rigorously determined sampling strata as the unit of aggregation, which makes the units of analysis homogeneous in both geographical and socio-economical terms.

The use of factor analysis has been criticized for its subjective nature, including consolidation of food items into food groups, the number of factors to be extracted and the methods of rotation and labelling ${ }^{(47,48)}$, and there is concern that results cannot be replicated across populations or even in the same population ${ }^{(36)}$.
In conclusion, on the basis of food acquisition data, two food patterns were observed in Brazil, namely dual and traditional, according to the food items that contributed to each pattern. Educational level, income and age were positively associated with the dual pattern, whereas the traditional pattern was inversely associated with educational level and was stronger in the rural setting. The results of the present study have important implications for nutrition prevention. Besides the fact that knowledge of the sociodemographic characteristics related to the patterns might help identify groups for target campaigns and interventions, the dietary patterns described here suggest that food programmes to promote healthy eating need to consider the fact that healthy and non-healthy foods may be integral in the same pattern.

\section{Acknowledgements}

The present research received no specific grant from any funding agency in the public, commercial and notfor-profit sectors. The authors have no conflict of interest to declare. D.M.M. conceived the study, was involved in the analysis and interpretation of the results and drafted the manuscript; R.M.C. and R.B.L. were involved in data preparation, analysis of the results and review of the manuscript; C.A.M. was involved in conceptualizing the study, interpretation of results and in critical review of the manuscript.

\section{References}

1. Coitinho D, Monteiro CA \& Popkin BM (2002) What Brazil is doing to promote healthy diets and active lifestyles. Public Health Nutr 8, 263-267.

2. Hoffmann K, Schulze M, Boeing H et al. (2000) Dietary patterns: report of an international workshop. Public Health Nutr 5, 89-90.

3. Schulze MB, Hoffmann KH, Kroke KA et al. (2003) An approach to construct simplified measures of dietary patterns from exploratory factor analysis. Br J Nutr 89, 409-418.

4. Newby PK, Muller D \& Tucker KL (2004) Associations of empirically derived eating patterns with plasma lipid biomarkers: a comparison of factor and cluster analysis methods. Am J Clin Nutr 80, 759-767.

5. Levy-Costa RB, Sichieri R, Pontes NS et al. (2005) Household food availability in Brazil: distribution and trends (1974-2003). Rev Saude Publica 39, 530-540.

6. Instituto Brasileiro de Geografia e Estatística (2004) Pesquisa de Orçamentos Familiares - POF 2002/2003: Análise da Disponibilidade Domiciliar de Alimentos e do Estado Nutricional no Brasil. Rio de Janeiro: IBGE.

7. Instituto Brasileiro de Geografia e Estatística (1978) Estudo Nacional das Despesas Familiares - ENDEF: 1974-1975. Rio de Janeiro: IBGE.

8. Núcleo de Pesquisas Epidemiológicas em Nutrição e Saúde da Universidade de São Paulo (2008) Conversor de Aquisições de Alimento em Energia e Nutrientes (AQUINUT), Version 1.0. http://www.fsp.usp.br/nupens/aquinut.zip (accessed August 2008). 
9. Núcleo de Estudos e Pesquisas em Alimentação (2004) Tabela Brasileira de Composição de Alimentos - TACO. Campinas: Flamboyant.

10. US Department of Agriculture, Agricultural Research Service (2002) USDA Nutrient Database for Standard Reference. Release 15. Washington, DC: USDA.

11. Kim J \& Mueller CW (1978) Factor Analysis: Statistical Methods and Practical Issues. Beverly Hills, CA: SAGE.

12. Hair JF, Anderson RE, Tatham RL et al. (2009) Multivariate Data Analysis with Readings, 7th ed. Englewood Cliffs, NJ: Prentice Hall.

13. Slattery ML, Boucher KM, Caan BJ et al. (1998) Eating patterns and the risk of colon cancer. Am J Epidemiol $\mathbf{4 8}$, $4-16$.

14. Schulze MB, Hoffmann KH, Kroke KA et al. (2001) Dietary patterns and their association with food and nutrient intake in the European Prospective Investigation into Cancer and Nutrition (EPIC) - Potsdam Study. $\mathrm{Br} \mathrm{J}$ Nutr 5, 363-373.

15. Willett W \& Stampfer MJ (1986) Total energy intake: implications for epidemiologic analyses. Am J Epidemiol 124, 17-27.

16. Edefonti V, Randi G, La Vecchia C et al. (2009) Dietary patterns and breast cancer: a review with focus on methodological issues. Nutr Rev 67, 297-314.

17. Fung T, Hu FB, Fuchs C et al. (2003) Major dietary patterns and the risk of colorectal cancer in women. Arch Intern Med 163, 309-314.

18. Wu K, Hu FB, Willett WC et al. (2006) Dietary patterns and risk of prostate cancer in U.S. men. Cancer Epidemiol Biomarkers Prev 15, 167-171.

19. Fu ML, Cheng L, Tu SH et al. (2007) Association between unhealthful eating patterns and unfavorable overall school performance in children. J Am Diet Assoc 107, 1935-1943.

20. Dixon LB, Balder HF, Virtanen MJ et al. (2004) Dietary patterns associated with colon and rectal cancer: results from the Dietary Patterns and Cancer (DIETSCAN) Project. Am J Clin Nutr 80, 1003-1011.

21. Kesse E, Clavel-Chapelon F \& Boutron-Ruault MC (2006) Dietary patterns and risk of colorectal tumors: a cohort of French women of the National Education System (E3N). Am J Epidemiol 164, 1085-1093.

22. Terry P, Suzuki R, Hu FB et al. (2001) A prospective study of major dietary patterns and the risk of breast cancer. Cancer Epidemiol Biomarkers Prev 10, 1281-1285.

23. Kim MK, Sasaki S, Otani T et al. (2005) Dietary patterns and subsequent colorectal cancer risk by subsite: a prospective cohort study. Int J Cancer 115, 790-798.

24. Mizoue T, Yamaji T, Tabata S et al. (2005) Dietary patterns and colorectal adenomas in Japanese men: the SelfDefense Forces Health Study. Am J Epidemiol 15, 338-345.

25. Hirose K, Matsuo K, Iwata H et al. (2007) Dietary patterns and the risk of breast cancer in Japanese women. Cancer Sci 98, 1431-1438.

26. Lee JE, Kim JH, Son SJ et al. (2011) Dietary pattern classifications with nutrient intake and health-risk factors in Korean men. Nutrition 27, 26-33.

27. Sichieri R (2002) Dietary patterns and their associations with obesity in the Brazilian city of Rio de Janeiro. Obes Res 10, 42-48.

28. Marchioni DML, Fisberg RM, Góis Filho JF et al. (2007) Padrões dietéticos e risco de câncer oral: estudo casocontrole em São Paulo. Rev Saúde Pública 41, 19-26.

29. Noel SE, Newby PK, Ordovas JM et al. (2009) A traditional rice and beans pattern is associated with metabolic syndrome in Puerto Rican older adults. J Nutr 139, 1360-1367.
30. Toledo AL, Koifman RJ, Koifman S et al. (2010) Dietary patterns and risk of oral and pharyngeal cancer: a case-control study in Rio de Janeiro, Brazil. Cad Saude Publica 26, 135-142.

31. Marchioni DM, Latorre Mdo R \& Eluf-Neto J (2005) Identification of dietary patterns using factor analysis in an epidemiological study in São Paulo. Sao Paulo Med J 123, 124-127.

32. Mikkilä V, Räsänen L, Raitakari OT et al. (2007) Major dietary patterns and cardiovascular risk factors from childhood to adulthood. The Cardiovascular Risk in Young Finns Study. Br J Nutr 98, 218-225.

33. Tseng M \& DeVellis RF (2001) Fundamental dietary patterns and their correlates among US whites. J Am Diet Assoc 101, 929-932.

34. Olinto MT, Willett WC, Gigante DP et al. (2011) Sociodemographic and lifestyle characteristics in relation to dietary patterns among young Brazilian adults. Public Health Nutr 14, 150-159.

35. Rezazadeh A, Rashidkhani B \& Omidvar N (2010) Association of major dietary patterns with socioeconomic and lifestyle factors of adult women living in Tehran, Iran. Nutrition 26, 337-341.

36. Hu FB, Rimm EB, Stampfer MJ et al. (2000) Prospective study of major dietary patterns and risk of coronary heart disease in men. Am J Clin Nutr 72, 912-921.

37. Whichelow MJ \& Prevost AT (1996) Dietary patterns and their associations with demographic, lifestyle and healthvariables in a random sample of British adults. BrJ Nutr 76, $17-30$.

38. Fan JX, Brown BB, Kowaleski-Jones L et al. (2007) Household food expenditure patterns: a cluster analysis. Mon Labor Rev 130, 38-51.

39. Cai H, Zheng W, Xiang YB et al. (2007) Dietary patterns and their correlates among middle-aged and elderly Chinese men: a report from the Shanghai Men's Health Study. Br J Nutr 98, 1006-1013.

40. Sánchez-Villegas A, Delgado-Rodríguez M, MartínezGonzález MA et al. (2003) Gender, age, socio-demographic and lifestyle factors associated with major dietary patterns in the Spanish Project SUN (Seguimiento Universidad de Navarra). Eur J Clin Nutr 57, 285-292.

41. Yang EJ, Kerver JM \& Song WO (2005) Dietary patterns of Korean Americans described by factor analysis. J Am Coll Nutr 24, 115-121.

42. Carrera PM, Gao X \& Tucker KL (2007) A study of dietary patterns in the Mexican-American population and their association with obesity. J Am Diet Assoc 107, 1735-1742.

43. Hamer M \& Mishra GD (2010) Dietary patterns and cardiovascular risk markers in the UK Low Income Diet and Nutrition Survey. Nutr Metab Cardiovasc Dis 20, 491-497.

44. Ministério da Saúde (2006) Guia Alimentar Para a População Brasileira: Promovendo Uma Alimentação Saudável. Guia Alimentar. Brasília: Ministério da Saúde.

45. Naska A, Vasdekis VGS \& Trichopoulou A (2001) A preliminary assessment of the use of household budget survey data for the prediction of individual food consumption. Public Health Nutr 4, 1159-1165.

46. Becker W (2001) Comparability of household and individual food consumption data - evidence from Sweden. Public Health Nutr 4, 1177-1182.

47. Martinez ME, Marshall JR \& Sechrest L (1998) Invited commentary: factor analysis and the search for objectivity. Am J Epidemiol 148, 17-19.

48. Jacques PF \& Tucker KL (2001) Are dietary patterns useful for understanding the role of diet in chronic disease? $A m \mathrm{~J}$ Clin Nutr 73, 1-2. 